\title{
A prática de slam no ensino de Literatura na EJA: refletindo um currículo antirracista
}

Giovanna Torres*

Juçara Benvenuti**

\begin{abstract}
Resumo:
Esse relato de experiência traz resultados obtidos a partir do sarau antirracista realizado na véspera do dia consciência negra, no dia 19 de novembro de 2019, com os alunos da modalidade de Educação de Jovens e Adultos (EJA) do Colégio de Aplicação (CAp/UFRGS). A atividade buscou potencializar ações de educação para as relações étnico-raciais, especialmente no que se refere ao ensino de Literatura. A participação do convidado Ariel Freitas, ativista, jornalista e poeta, trouxe a prática de poetry slams, sendo essa uma categoria literária ainda pouco reconhecida em ambientes tradicionais, surgida a partir de competições de poesia falada, e que "vêm figurando entre as mais inventivas e democráticas práticas da poesia performática em todo o mundo, com notáveis aspectos sociais, culturais, políticos e artísticos" (D'ALVA, 2019, p. 269). Busca-se, a partir desse relato, promover uma reflexão acerca da necessidade de incluir cada vez mais pautas raciais no currículo do ensino básico, pensando especialmente a categoria da EJA, a mais atingida pelo analfabetismo, e nos empecilhos que muitos alunos encontram para acessar uma ferramenta básica e essencial para o pleno exercício da cidadania: a escrita.
\end{abstract}

\section{Palavras-chave:}

Slam. Educação antirracista. Poesia falada.

\section{Resumen:}

Este relato de experiencia trae los resultados obtenidos en un recital antirracista consumado en la víspera del día de la conciencia negra, el 19 de noviembre de 2019, con estudiantes de la modalidad de Educación para Jóvenes y Adultos (EJA) del Colégio de Aplicação (CAp/UFRGS). La actividad buscó mejorar las acciones educativas para las relaciones étnico-raciales, especialmente con respecto a la enseñanza de la literatura. La participación del invitado Ariel Freitas, activista, periodista y poeta, trajo la práctica de la poetry slams, siendo esta una categoría literaria aún poco reconocida en ambientes tradicionales, que surge en competiciones de poesía hablada, y que "han estado entre

\footnotetext{
* Graduanda em Letras da Universidade Federal do Rio Grande do Sul (UFRGS) e bolsista de Iniciação Científica pelo CNPq no projeto denominado "CAp/UFRGS: uma trajetória inovadora na construção metodológica e curricular de projetos para EJA". E-mail: giovannademedeiros@hotmail.com. ORCID iD: https://orcid.org/000-0003-0229-2708.

** Doutora em Educação pela FACED, professora titular de Língua Portuguesa e Literatura, oferece oficinas e orienta Projetos de Investigação nas turmas de Educação de Jovens e Adultos do CAp/UFRGS, bem como desenvolve pesquisas interdisciplinares com esta modalidade de ensino. E-mail: benvenuti@ufrgs.br. ORCID iD: https://orcid.org/0000-0003-0243-0373.
} 
las más ingeniosas y democráticas prácticas de la poesía de performance en todo el mundo, con notables aspectos sociales, culturales, políticos y artísticos" (D'ALVA, 2019, p. 269). A partir de este informe, buscamos promover una reflexión sobre la necesidad de incluir cada vez más agendas raciales en el plan de estudios de educación básica, especialmente pensando en la categoría de EJA, la más afectada por el analfabetismo, y en los obstáculos que muchos estudiantes encuentran para acceder una herramienta básica y esencial para el pleno ejercicio de la ciudadanía: la escrita.

\section{Palabras-clave:}

Slam. Educación antirracista. Poesía hablada.

\section{A EJA, o analfabetismo e as relações étnico-raciais}

O processo de ensino-aprendizagem na modalidade Educação de Jovens e Adultos (EJA) é permeado por nuances inerentes à natureza do público a que se direciona essa educação, geralmente constituída por trabalhadores, que não conseguiram concluir os estudos no tempo estipulado pela modalidade regular. Diante disso, é necessário discutir o ensino de Literatura no contexto dos cursos de EJA, nos quais muitas vezes os alunos acessam as variantes não prestigiadas da língua e têm pouco ou nenhum acesso à literatura fora do ambiente escolar.

Apesar de todas as mudanças e avanços com relação ao acesso à educação formal que vem sendo implantadas, o analfabetismo - absoluto e funcional - segue sendo um problema que predomina na sociedade. As pesquisas mostram que o acesso à leitura e à escrita se evidencia e anda lado a lado com a desigualdade racial, como descrito a seguir:

$\mathrm{Na}$ análise por cor ou raça, em 2018, 3,9\% das pessoas de 15 anos ou mais, de cor branca, eram analfabetas, percentual que se eleva para $9,1 \%$ entre pessoas de cor preta ou parda. No grupo etário 60 anos ou mais, a taxa de analfabetismo das pessoas de cor branca alcança 10,3\% e, entre as pessoas pretas ou pardas, amplia-se para 27,5\%. (IBGE, 2019).

Analisando dados mais antigos do IBGE, observa-se que em 2010 o Brasil possuía 12.893 .141 milhões de pessoas, de 15 anos ou mais, na condição de analfabetas. Entre estas, 66,7\% eram pessoas negras. Diante desses números alarmantes, o Instituto Nacional de Estudos e Pesquisas Educacionais Anísio Teixeira (INEP) constatou que, em 2015, apenas 3.738 .852 milhões de pessoas estavam matriculadas em turmas de EJA para conclusão do Ensino Fundamental. Conforme pontuado no artigo "A educação das relações étnico-raciais na EJA", "os números são reveladores das desigualdades na escolarização em particular da população negra, além de evidenciar que as instituições educacionais não absorvem a demanda real das pessoas focalizadas pela EJA" (PASSOS; SANTOS, 2018, p. 3).

Segundo especialistas, a quantidade de analfabetos ainda é grande devido à falta de investimento direto na EJA, fato que é sustentado por argumentos que partem de um pretexto muito errôneo de que é apenas necessário e prioritário investir nas novas gerações, pois, com isso, o analfabetismo será erradicado, fazendo com que a sucessão geracional se encarregue de acabar com o problema. Esse argumento é refutado por Maria Clara Di Pierro, professora de Educação da Universidade de São Paulo (USP), especializada em políticas públicas de jovens e adultos, que argumenta, em entrevista para o site Agência Brasil:

De um lado, porque a gente continua produzindo analfabetismo, não se trata apenas de um resíduo do passado e os idosos estão vivendo mais. De outro lado, nós temos o analfabetismo funcional mediado pelo sistema educativo. Então, essa esperança "vamos deixar os velhinhos morrerem para acabar com o problema” é uma ilusão, e não faz frente ao que temos de enfrentar. (COSTA, 2019). 
Conforme pontuado pela educadora, ainda temos a continuidade de outro problema que atinge dados ainda mais alarmantes: $\mathrm{o}$ analfabetismo funcional, definido como a capacidade de compreender e utilizar a informação escrita e refletir sobre ela. Um estudo que se preocupou em medir esses números é denominado Indicador de Alfabetismo Funcional, elaborado pelo Instituto Paulo Montenegro e pela Ação Educativa, que determinou apenas $12 \%$ da população como "proficiente" e que $29 \%$ das pessoas podem ser consideradas analfabetas funcionais, segundo testes cognitivos aplicados em 2002 (habitantes de áreas urbanas e rurais).

Segundo Costa (2019), "a proporção de analfabetos funcionais no Brasil totaliza 38 milhões de pessoas. O volume dessa população é maior que quase todos os estados brasileiros, só perde para o total de residentes no Estado de São Paulo (41,2 milhões)". Nesse sentido, é preciso analisar o papel da oralidade na esfera comunicativa do português brasileiro, refletindo acerca das dificuldades no aprendizado de língua portuguesa no país e sobre a falta de um projeto de ensino em esfera nacional. A tese é que parte do problema advém de distanciamentos existentes entre a língua falada e a escrita e às circunstâncias que se produziram no Brasil para a implementação de um ensino de Língua Portuguesa pautado em um modelo de uso europeu, que pode ajudar a afastar os falantes do nosso país de sua própria língua nativa.

A solução reside, então, na utilização da oralidade como um mecanismo de acesso à literatura, incluindo temas educacionais que reflitam sobre a história e a cultura africana e afro-brasileira e implantando as relações étnico-raciais como centrais em todas as disciplinas escolares. É preciso urgentemente falar de práticas de ensino palpáveis para que não se recorra sempre à teoria sem a prática, e os slams têm - conforme será explicitado mais adiante - a capacidade de unir essas demandas e vem demonstrando seu imenso potencial educacional nas mais diversas etapas do aprendizado escolar, com enfoque especial nos alunos da modalidade de EJA.

\section{Oralidade e tecnologia no Brasil: do rádio ao Spotify}

Observamos, na última década, um crescimento acelerado e exacerbado das plataformas audiovisuais da Internet. Em um número cada vez mais exponencial, esses ambientes têm expandindo suas abordagens em direção aos jornais, revistas e noticiários, incluindo, em quantidades ainda maiores, os mais variados tipos de produções artísticas e literárias e "democratizando", em certa medida, o acesso a esses conteúdos diversos.

No contexto do Brasil, é preciso levar em consideração a importância das primeiras mídias auditivas, principalmente o rádio, na veiculação não só de notícias, mas também como um grande (e, antigamente, $o$ único) difusor cultural popular, fenômeno que ocorrreu principalmente após a década de 1930, atingindo com maior alcance as classes menos abastadas após o término da Segunda Guerra Mundial. Essa relevância às vezes é desconsiderada, porém é essencial para entender como o sistema de radiodifusão e as músicas educaram muitas gerações, sendo esse veículo extremamente central para a comunicação e informação em um "país de analfabetos", estando, assim, ligadas diretamente a questões que permeiam o uso da oralidade na educação.

Em uma entrevista internacional ao jornal El País, Caetano Veloso, quando questionado sobre o porquê de, no Brasil, quando fatos importantes acontecem, os artistas são chamados a se pronunciar, e não os especialistas da área, respondeu que é porque o Brasil é um país de analfabetos. Assim, a música e as grandes mídias educaram e educam grande parte da população, e é por isso que os artistas ficam em evidência sempre que algo precisa ser debatido em esfera nacional.

Em outro momento, Caetano comenta:

Creio que uma das características mais desafiadoras e inspiradoras do Brasil é o fato de falar português. É o único país das Américas em que se fala português, e um país de dimensões continentais, no hemisfério sul, onde vive a maior população negra fora do continente africano. Sempre cheio de promessas e sempre falido. Esse vínculo linguístico-histórico com Portugal me parece um grande desafio e aumenta nossa responsabilidade de criar algo original no mundo. É uma inevitabilidade da condição do brasileiro. (GALILEA, 2014). 
A observação do cantor é interessante para nossa discussão, pois acentua a problemática de um ensino de português pautado em um uso luso-europeu, que dificulta o processo de ensino-aprendizagem da língua. De fato, o radialismo, unido à música popular brasileira, exerceram papéis centrais na comunicação e informação da população em tempos que a imensa maioria não tinha acesso à escolarização, e em que muitos ainda eram analfabetos. A oralidade, então, se ocupava de informar e debater desde os fatos mais rotineiros aos mais complexos, se encarregando também de proporcionar a difusão cultural e o entretenimento.

Dessa forma, o rádio (e, aqui, incluímos a música), segundo Horta (1972, p. 117), "é muito mais um instrumento de ensino do que de educação, é muito mais um meio de transmissão de conhecimentos e comunicados do que um meio de comunicação". Esse papel central de difusão e transmissão de informações foi de extrema importância para a inclusão de analfabetos no debate público, levando conhecimento e mudando perspectivas, podendo, segundo Baumworcel (2008, p. 12), "participar do processo de mudanças sociais, quando reforça a luta pelos direitos de grupos ou classes sociais [...], assim como da manutenção de padrões estabelecidos, podendo oscilar entre um lugar de reprodução e de transformação”.

Dito isso, chegamos a um momento crucial da humanidade, em que, apesar de a grande maioria da população mundial ser hoje alfabetizada, a oralidade, começa, novamente, a ocupar um papel central na difusão de informações. Isso se dá tanto pela facilidade de difusão por meio da fala, sendo ela considerada "fluída" e de fácil entendimento, quanto pela falta de tempo ocasionada pelo mundo moderno, que dá pouco espaço para o ócio e para prazeres como a leitura, especialmente nos casos de trabalhadores terceirizados e subutilizados, atingidos por cargas horárias imensas e jornadas pesadas de trabalho.

Vale lembrar ainda que, na modalidade EJA, a oralidade ocupa um lugar especialmente importante por ser constituída predominantemente por um público que atua nos trabalhos e profissões de base e por conta dos altos níveis de analfabetismo antes mencionados. Além disso, é importante mencionar outro fenômeno relacionado à aquisição da leitura e da escrita que não se vincula diretamente com o grau de escolarização: o letramento, entendido como o uso social da língua em atividades de leitura e escrita na vertente defendida por Magda Soares (1998, 2003).

Oralidade e letramento são práticas sociais complementares de uso da linguagem. As regras da língua surgem a partir dos usos, ou seja, é da oralidade que surge a escrita e não o contrário. A escrita não deixa de ser uma tecnologia essencial para a sobrevivência no mundo moderno. Porém, a sociedade brasileira em si se constitui em uma esfera que não é letrada, que consome arte, cultura e informação de uma forma oral e visual (telenovelas, televisão, rádio) justamente por conta dessa falta de letramento da população. Assim, a escrita não pode ser vista como representante da fala porque não reproduz muitas coisas que envolvem a oralidade. Os usos e papéis que a escrita e a leitura exercem na sociedade que configuram o "letramento". Assim, letramento não é sinônimo de alfabetização, pois inclusive os analfabetos estão inseridos na esfera de letramento quando vão pegar um ônibus, por exemplo. O letramento é entendido, então, como um processo de aprendizagem social e histórica da leitura e da escrita em contextos informais e para usos mais imediatos.

Esse pensamento "grafocêntrico" que concede apenas a escrita um lugar de destaque e de legitimidade em detrimento da oralidade é refletido por Eugênio Freire (2013, p. 42), e tem, segundo ele,

[...] teor paralisante aos iletrados por meio da propagação do entendimento que os analfabetos (ou pouco alfabetizados) encontram-se distantes do pensamento lógico, reforçando a valoração negativa desse grupo que, geralmente associado s classes de menor renda, já se vê costumeiramente agredido por valores desabornadores e privações.

Apesar disso, plataformas como o Spotify vêm se difundido e ganhando destaque principalmente entre a chamada Geração Y (os millennials), sendo, no Brasil, a plataforma de streaming (acesso online a um catálogo de músicas ilimitado em distribuição digital) número 1, com percepção mais alta entre os adolescentes. Além do recurso de distribuição musical ilimitada com playlists direcionadas por uma curadoria que seleciona e guia a experiência do usuário de acordo com seu perfil, temos o crescimento de recursos informativos e literários nessa mesma plataforma: os podcasts. Eles são, nada menos do que, um recurso 
de aúdio transmitido por meio da Internet, sobre os mais variados conteúdos, como livros, meditações, poesias, aulas de idiomas estrangeiros e até mesmo notícias jornalisticas diárias ${ }^{1}$.

Essa retomada histórica feita até aqui acerca da trajetória da oralidade na EJA (passando pela alfabetização) e o espaço que ela ocupa na sociedade contemporânea atual (exemplificado a partir do advento das rádios e do Spotify) tem o objetivo de demonstrar o poder que a voz humana tem e a força que sua mensagem chega ao receptor, carregando uma série de experiências pessoais e proporcionando o envolvimento com seu discurso, como é explicitado na citação que se segue:

Sua mensagem chega ao receptor como uma impressão de experiência pessoal, proporcionando um envolvimento com seu discurso, que permite ao ouvinte criar imagens e gerar emoções. A voz humana persuade por expressar o sentimento humano, independentemente do conteúdo das palavras que são ditas. A voz humana é um termômetro infalível das emoções e é a voz que contribui para dar "imagem" às palavras. (BAUMWORCEL, 2008, p. 5).

A poesia e a literatura, não obstante, tomam formas totalmente diferentes quando interpretadas de forma oral, podendo carregar força, emoções e dando ainda mais literariedade às palavras antes escritas. Envolvem e seduzem o interlocutor, fazendo com que a mensagem chegue ainda mais longe, e inclui entre seus ouvintes os que antes eram especialmente excluídos dessa arte: os analfabetos. Dessa forma, a seguir investigaremos as raízes dos poetry slams para compreender melhor como o movimento foi utilizado na aprendizagem escolar de nosso relato de experiência, investigando seu potencial literário e suas contribuições à oralidade.

\section{Os poetry slams no ensino de Literatura: um relato de experiência}

O movimento literário denominado poetry slam surgiu em 1986, em Chicago, a partir da iniciativa de um bar de deixar o microfone aberto para que as pessoas pudessem declamar seus textos, criando um encontro não só artístico, mas que atravessa temas delicados, muitos de cunho socio-cultural. Como bem descreve D’Alva (2019, p. 270):

sua popularização se deu como uma resposta à ideia elitista de que a poesia seria um gênero restrito aos círculos acadêmicos; que pertenceria exclusivamente a um ou outro determinado grupo social específico; ou mesmo que existiria somente enquanto manifestação escrita.

Os poetry slams, então, ou simplesmente slams, ganharam força a partir dessa iniciativa única de democratizar o acesso à literatura e à poesia, fazendo uso da autoria e da livre expressão poética, agregando consigo vários fatores cênicos e contando com a participação do público envolvido. Essas apresentações podem ser figuradas em diversos formatos, nos quais precisam ser utilizados textos autoriais e curtos, declamados de forma rápida ( 3 a $5 \mathrm{~min}$ ), sem nenhum acompanhamento musical, figurinos ou adereços e, geralmente, tem a participação de um júri escolhido aleatoriamente entre o público. Seu formato é orgânico e se utiliza das feramentas mais básicas da comunicação: a voz, o gesto e a palavra.

O enorme potencial dos slams enquanto movimento social, cultural e artístico se dá por seu uso como uma plataforma de expressão literária e poética livre, que agrega uma diversidade nunca antes relatada nesse meio. $\mathrm{O}$ movimento não está dissociado de seu caráter extremamente político na medida em que inclui os antes excluídos e dá voz aos antes silenciados. Segundo D’Alva (2019, p. 271), “a auspiciosa junção de política, arte, entretenimento e jogo, somada à sua vocação comunitária, fazem com que os slams sejam celebrados em comunidades no mundo todo, com realidades completamente distintas". 
Pensando em todo esse potencial como ferramenta de expressão, parece natural perceber que os slams estão muito além de serem somente uma forma de entretenimento, pois se configuram como um grande mecanismo de formação educacional. Sua relação com a oralidade é particularmente especial e, pensando na realidade objetiva de nosso país em termos de alfabetização e leitura, é compreensível que eles ocupem aqui um grande espaço, preconizado principalmente pelo público jovem e periférico, em um momento tão crítico na esfera política da nossa sociedade, como complementa D’Alva (2019, p. 271), na citação a seguir:

Em um momento em que as forças conservadoras se levantam e tentam agarrar-se aos velhos dogmas e posturas, buscando desesperadamente manter o estado de opressão estabelecido, há, em curso, também um levante de manifestações da poesia popular urbana, principalmente a falada e performática. Os slams de poesia vêm se proliferando em grande progressão, organizando vozes que emanam do povo em ágoras democráticas e auto-geridas [sic]. Vozes que, juntas, transformam em realidade a possibilidade do encontro, do debate e da celebração.

Parece-nos ainda mais evidente sua correlação com a modalidade de ensino da Educação de Jovens e Adultos (EJA), que, conforme explicitado ao longo do texto, assume características majoritariamente populares por conta de seu público que têm, muitas vezes, seus saberes marginalizados e possui pouco ou nenhum acesso à literatura escrita. O slam passa, então, a aproximar públicos cada vez maiores da poesia e da literatura, que antes eram considerados gêneros entendiantes, pacatos e incapazes de gerar interesse, em uma década em que cada vez mais nossos jovens e adultos se distanciam dessas categorias, e preenche uma enorme lacuna que resulta da falta de acesso, principalmente entre o público da EJA. Intencionando demonstrar de forma prática como os slams podem ser bem utilizados dentro ambiente escolar e seu enorme potencial de ensino, a seguir temos nosso relato de experiência realizado durante um sarau antirracista no Colégio de Aplicação da UFRGS (CAp/UFRGS).

\section{Sarau antirracista}

O Colégio de Aplicação (CAp) da UFRGS está sediado no Campus do Vale e atende estudantes desde o primeiro ano do Ensino Fundamental até o último ano do Ensino Médio nas duas modalidades de ensino: regular e EJA. A escola prioriza atividades interdisciplinares, e por estar sediada dentro do campus universitário da UFRGS, recebe permanentemente alunos das graduações que visam fazer estágios, serem bolsistas - monitoria e Iniciação Científica (IC) - ou colocar em prática algum de seus projetos sob supervisão dos professores do CAp. Isso faz com que a escola se destaque entre rankigs na qualidade da educação, pois investe nas ideias inovadoras da juventude universitária e na autonomia de seus alunos, além de priorizar sempre a formação do pensamento crítico dos estudantes, contribuindo para o desenvolvimento de cidadãos conscientes e atuantes na sociedade.

Os professores, unidos aos gestores da escola, sempre realizam atividades de conscientização durante todo mês de novembro, no qual dia 20 é celebrado o dia da consciência negra. Em 2019, a iniciativa mais expressiva na modalidade da EJA foi a realização do sarau antirracista, concretizado na véspera do dia consciência negra, no dia 19 de novembro. A atividade ${ }^{2}$ buscou potencializar ações de educação para as relações étnico-raciais, especialmente no que se refere ao ensino de Literatura.

Levando-se em consideração a capacidade dos poetry slams de educar e aproximar os alunos da Literatura e da Arte, surgiu a ideia de convidar para o sarau o ativista, jornalista e poeta Ariel Freitas, uma figura atuante na militância negra jovem portoalegrense. O convidado trouxe, então, a prática dos slams, e

\footnotetext{
2. O sarau foi idealizado por iniciativa dos professores do Bloco de Humanidades que oferecem a Oficina Intervenções. Ampliada a proposta inicial, outras participações foram se aderindo como os professores e bolsistas do Bloco de Comunicação, que ampliaram a atividade com convidados externos ao CAp e trouxeram o slam para o evento.
} 
declamou seus textos autorais que emocionaram os estudantes ali presentes e posteriormente encorajou-os a participar da prática poética.

Ariel deu início à sua apresentação com uma declamação que dizia o seguinte:

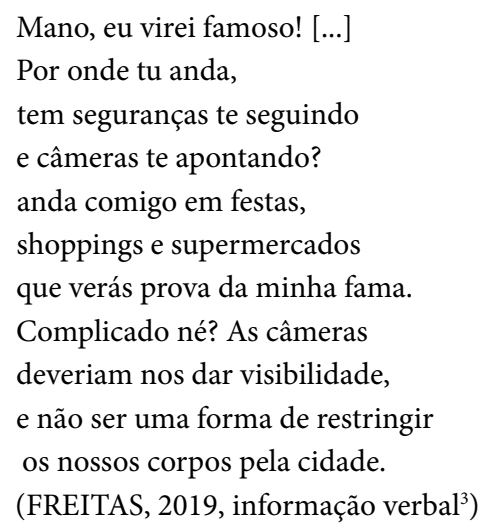

E ele segue, dizendo:

Aprendi que, sou burro demais para academia, academico demais para a periferia.

Esses são espaços sociais e contradições que enfrento no meu dia a dia. Eu quero muito mais do que uma universidade com portas abertas que ja é pública, eu quero que a pretinha retinta de black entenda que sua beleza é única.

Eu quero que o pretinho, com dread ou sem, entenda que não precisa mirar no horizonte, pois ele nasceu para ir além. [...]

Eu sou um jovem príncipe negro de 23 anos, vivendo a vida com medo dos 23 minutos, pois tenho mô medo de ver minha coroa colocar no facebook: LUTO.

(FREITAS, 2019, informação verbal)

As palavras do convidado foram especialmente tocantes no contexto do dia da consciência negra. A declamação, a gesticulação e a voz possuía uma força enorme que expressava a representatividade e a necessidade de incluir no âmago das instituições de ensino básico um debate aberto e essencial sobre a questão racial no Brasil. Esses espaços precisam ser consolidados.

Com muitas palmas, Ariel seguiu sua apresentação. A partir dele, nós, do setor de Língua Portuguesa, incentivamos outros alunos a declamarem poemas. Depois da identificação quase imediata de alguns estudantes com a fala de Ariel, o aluno Thiago escolheu declamar um texto do próprio convidado, que está com trechos transcritos a seguir:

Ser negro no Brasil é viver com a cabeça recheadas por números.

Eu odeio números. Sempre odiei, mas eles não deixam que eu minta.

Ser negro no Brasil é rezar pra chegar vivo aos 30.

[...] Agora, se eu fizer uma pergunta, vou cutucar sua ferida.

Me diz aí, quantos professores negros vocês tiveram na vida?

(FREITAS, 2017).

3. Informação oral obtida em sarau proferido por ocasião do Dia da Consciência Negra no Colégio de Aplicação da UFRGS (CAp/ UFRGS) em 2019. 
A forma como essa apresentação fez todos os presentes refletirem sobre o seus próprios lugares sociais e o papel que isso desempenha para a manutenção do racismo estrutural foi impressionante. Apesar de o tema ser constantemente debatido pela instituição de ensino que, como já citado, é politizada e busca incluir essas pautas no currículo, a apresentação trouxe uma força enorme para o debate e deu motivação para que mais alunos se pronunciassem. Depois disso, outras três alunas da EJA foram encorajadas a fazer leituras em voz alta dos escritos da Djamila Ribeiro, da Carolina de Jesus e da Conceição Evaristo.

A aluna Paula, que estava cursando o Ensino Médio, declamou para os colegas o seguinte poema:

$$
\begin{aligned}
& \text { [...] A minha voz ainda } \\
& \text { ecoa versos perplexos } \\
& \text { com rimas de sangue } \\
& \text { e fome. } \\
& \text { A voz de minha filha } \\
& \text { recolhe todas as nossas vozes } \\
& \text { recolhe em si } \\
& \text { as vozes mudas caladas } \\
& \text { engasgadas nas gargantas. } \\
& \text { A voz de minha filha } \\
& \text { recolhe em si } \\
& \text { a fala e o ato. } \\
& \text { O ontem - o hoje - o agora. } \\
& \text { Na voz de minha filha } \\
& \text { se fará ouvir a ressonância } \\
& \text { O eco da vida-liberdade. } \\
& \text { (EVARISTO, 2008, p. 10-11). }
\end{aligned}
$$

Já Desirée Shayane, aluna do Ensino Fundamental, leu o trecho de Carolina Maria de Jesus, que está abaixo:

A vida é igual um livro. Só depois de ter lido é que sabemos o que encerra. E nós, quando estamos no fim da vida, é que sabemos como a nossa vida decorreu. A minha, até aqui, tem sido preta. Preta é a minha pele. Preto é o lugar onde eu moro. (JESUS, 1960, p. 143).

Figura 1 - Da esquerda para a direita: a aluna do Ensino Médio, Paula Guedes, declamando Conceição Evaristo; o escritor Ariel Freitas, declamando poemas autorais; e a aluna do Ensino Fundamental, Desireé Shayane, lendo Carolina Maria de Jesus

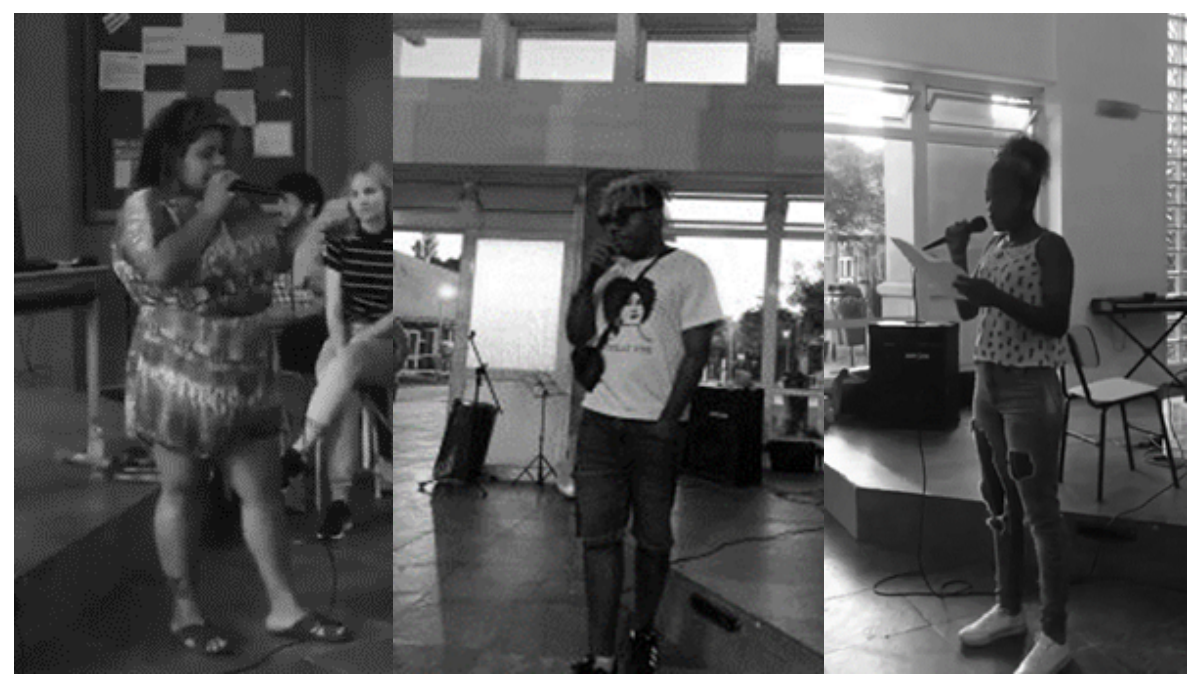

Fonte: Acervo das autoras. 


\section{Considerações finais}

Esse relato de experiência trouxe a reflexão acerca da necessidade de olhar para as demandas que surgem no debate público, especialmente do que diz respeito ao racismo estrutural e a representividade negra nas instituições.

Demonstrou, também, a forma como a juventude se reinventa e cria aparatos de fala e novas expressões de arte, como a prática do slam, que tem crescido e se consolidado principalmente pelo seu alcance e pela forma como consegue transmitir e propor debates entre os mais jovens, trazendo o lugar da oralidade e da escuta na Educação.

Reflete, ainda, de maneira eficaz, formas inovadoras de ensinar poesia e literatura no Ensino Básico, e levar a arte e a cultura periférica para dentro do currículo escolar, pensando em aproximar o ensino da realidade dos alunos e acrescentar subsídios para suas trajetórias pessoais e acadêmicas, estimulando a criatitividade, autonomia e autoria dos mesmos.

Todo esse movimento inovador também pode ser visto como uma forma de integração curricular entre as diversas matérias ensinadas, em especial no que diz respeito à Língua Portuguesa, Literatura, Arte e Teatro, visando aumentar as possibilidades para a integração pessoal e social através de um currículo em torno de problemas e de questões significantes, solucionando os empecilhos advindos de uma educação segmentada.

O lugar da EJA no Ensino Básico e suas singularidades curriculares também são questões norteadoras desse relato de experiência, que busca demonstrar, por meio das evidências aqui colocadas, a necessidade de reinventar as grades curriculares dessa modalidade, promovendo a interdisciplinariedade e fazendo bom uso da herança cultural desses alunos, pensando na definição dada por Bordieu para capital cultural (BORDIEU, 1998). Segundo o mesmo, os detentores do "capital cultural”, ou conhecimento erudito, possuem mais facilidade ao se depararem com o mesmo tipo de conhecimento nas instituições escolares, enquanto os que não o tem acabam sendo marginalizados no ensino regular, e a escola passa a ser, então, uma grande reprodutora de desigualdades sociais. O movimento de olhar para os saberes dos alunos e trazê-los para sala de aula desconstrói o ciclo reprodutor de desigualdades e contribui para o processo de ensino-aprendizagem desse alunado.

Se faz, ainda, necessário dar continuidade a esse projeto em sala de aula, investindo em um ensino de Literatura mais dinâmico e atrelado às vivências dos alunos, podendo até mesmo correlacionar o ensino de poesia, slam e música popular brasileira, por exemplo. Como o semestre estava acabando, não houve tempo hábil para a aplicação de um questionário para obtenção de um feedback dos alunos acerca dessa experiência, ou para dar continuidade ao projeto em sala de aula, novamente impedido de continuar em 2020, devido a pandemia de coronavírus mundial que estamos enfrentando. Porém, pretende-se dar continuidade ao projeto tão logo as aulas sejam retomadas, investindo cada vez mais na autoria desses alunos e na capacidade de criação poética sobre suas próprias trajetórias, e refletindo sobre a criação de um curríulo antirracista para o ensino de Língua Portuguesa e Literatura.

Assim sendo, conclui-se que podemos explorar as subjetividades dos alunos em suas trajetórias e performances, mudando paradigmas e dando autonomia para os mesmos interpretarem, declamarem e contarem suas histórias, sem deixar de propor debates essenciais para a sociedade. É urgente pensar em formas de reinventar o ensino de Literatura, e com a mesma urgência precisamos trazer pautas antirracistas e colocar propostas de ensino em vigor que levem em consideração esse debate tão importante para compreendermos o mundo. 


\section{Referências}

BAUMWORCEL, Ana. As escolas radiofônicas do MEB. In: CONGRESSO DE HISTÓRIA DA MÍDIA, 6., 2008, Niterói. Anais [...]. Niterói: UFF, 2008.

BORDIEU, Pierre. Escritos de Educação. Petrópolis: Vozes, 1998.

COSTA, Gilberto. Analfabetismo resiste no Brasil e no mundo do século 21. Agência Brasil, Brasília, DF, 8 set. 2019. Disponível em: https://agenciabrasil.ebc.com.br/educacao/noticia/2019-09/analfabetismo-resiste-no-brasil-e-nomundo-do-seculo-21. Acesso em: 14 ago. 2020.

D’ALVA, Roberta Estrela. SLAM: voz de levante. Rebento, São Paulo, n. 10, p. 268-286, jun. 2019. Disponível em: http://www.periodicos.ia.unesp.br/index.php/rebento/article/view/360/251. Acesso em: 14 ago. 2020.

EVARISTO, Conceição. Vozes-Mulheres. In: EVARISTO, Conceição. Poemas de recordação e outros movimentos. Belo Horizonte: Nandyala Livros, 2008. p. 10-11. Disponível em: http://www.letras.ufmg.br/literafro/24-textos-dasautoras/923-conceicao-evaristo-vozes-mulheres. Acesso em: 14 maio 2021.

FREIRE, Eugênio Paccelli Aguiar. Podcast na educação brasileira: natureza, potencialidades e implicações de uma tecnologia da comunicação. 2013. Tese (Doutorado em Educação) - Universidade Federal do Rio Grande do Norte, Natal, 2013. Disponível em: https://repositorio.ufrn.br/jspui/bitstream/123456789/14448/1/PodcastEduca\%C3\%A7\% C3\%A3oBrasileira_Freire_2013.pdf. Acesso em: 29 out 2020.

FREITAS, Ariel. Ser negro no Brasil é. Medium, United States, 26 dez. 2017. Disponível em: https://ariielfreitas.medium.com/ ser-negro-no-brasil-\%C3\%A9-102dc800725c. Acesso em: 14 ago. 2020.

GALILEA, Carlos. Caetano Veloso: “Criou-se uma imagem positiva do Brasil totalmente exagerada”. El País, Espanha, 24 maio 2014.

HORTA, José Silvério Baia. Histórico do rádio educativo no Brasil (1922-1970). Cadernos da PUC-Rio, Rio de Janeiro, n. 10, p. 73-123, set. 1972.

IBGE. PNAD Contínua 2018: educação avança no país, mas desigualdades raciais e por região persistem. Agência de Notícias - IBGE, Rio de Janeiro, 19 jun. 2019. Disponível em: https://agenciadenoticias.ibge.gov.br/agencia-sala-deimprensa/2013-agencia-de-noticias/releases/24857-pnad-continua-2018-educacao-avanca-no-pais-mas-desigualda des-raciais-e-por-regiao-persistem. Acesso em: 29 out. 2020.

JESUS, Carolina de. Quarto de despejo: diários de uma favelada. São Paulo: Círculo do Livro, 1990.

PASSOS, Joana Célia dos; SANTOS, Carina Santiago dos. A educação das relações étnico-raciais na EJA: entre as potencialidades e os desafios da prática pedagógica. Eduação em Revista, Belo Horizonte, v. 34, e192251, nov. 2018. Disponível em: http://www.scielo.br/scielo.php?script=sci_arttext\&pid=S0102-46982018000100654\&lng=pt\&nrm=iso. Acesso em: 06 jun. 2020.

SOARES, Magda. Letramento e escolarização. In: RIBEIRO, Vera Masagão. Letramento no Brasil: reflexões a partir do INAF 2001. São Paulo: Global, 2003. p. 89-113.

SOARES, Magda. Letramento: um tema em três gêneros. Belo Horizonte: CEALE/Autêntica, 1998.

\section{Outras obras utilizadas durante a execução do projeto}

CAVALCANTI, Rafael. Leitura na era digital é o tema da redação da UFRGS 2016. Zero Hora, Porto Alegre, 11 jan. 2016. Disponível em: https://gauchazh.clicrbs.com.br/educacao-e-emprego/noticia/2016/01/leitura-na-era-digitale-o-tema-da-redacao-da-ufrgs-2016-4948945.html. Acesso em: 14 ago. 2020.

O RÁDIO vs. Apps de Música (Spotify e cia): Quem é mais popular? VIRTUALcast, São Paulo, 31 dez. 2018. Disponível em: https://www.virtualcast.com.br/radio-fm-e-am-vs-apps-de-musica-spotify-deezer-etc-quem-e-mais-popular/ \#.XuAPGkVKiUk. Acesso em: 14 ago. 2020.

SIGNIFICADO de Podcast. Significados, 19 nov. 2020 (atualização). Disponível em: https://www.significados.com.br/ podcast/\#: :text=Podcast\%20\%C3\%A9\%20um\%20arquivo\%20digital,o\%20prop\%C3\%B3sito\%20de\%20transmitir\% 20informa\%C3\%A7\%C3\%B5es.\&text=Diferente\%20dos\%20feeds\%20de\%20texto,\%2C\%20\%22textos\%20para\% 20ouvir\%22. Acesso em: 14 ago. 2020. 
SPOTIFY espera substituir a literatura no futuro próximo? O Paraná, Cascavel, 3 abr. 2019. Disponível em: https:// oparana.com.br/noticia/spotify-espera-substituir-a-literatura-no-futuro-proximo/. Acesso em: 14 ago. 2020.

USO da tecnologia faz com que estudantes esqueçam livros. Veja, São Paulo, 22 ago. 2011. Disponível em: https:// veja.abril.com.br/educacao/uso-da-tecnologia-faz-com-que-estudantes-esquecam-livros/. Acesso em: 14 ago. 2020.

VAZ, Jaqueline. Dia Mundial da Alfabetização: o EJA combate o analfabetismo brasileiro. E+B Educação, 6 set. 2019. Disponível em: https://www.educamaisbrasil.com.br/educacao/escolas/dia-mundial-da-alfabetizacao-o-ejacombate-o-analfabetismo-brasileiro. Acesso em: 14 ago. 2020.

Data de submissão: 16/08/2020

Data de aceite: $31 / 08 / 2020$ 